\title{
ARTICLES
}

\section{UNDERSTANDING THE NATURE AND EFFECTS OF POLICE-CITIZEN ENCOUNTERS IN SOCIAL CONTEXT: A ROAD LESS TRAVELED}

\author{
Alfred R. D'Anca \\ College of Mount Saint Vincent
}

The practice of stop, question, and frisk (hereto referred to as "stop and frisk") by police officers, legally justified on the basis of reasonable suspicion of illicit behavior, represents a controversial issue of recurrent public concern, and has had pervasive undertones in diverse racial-ethnic urban neighborhood communities in which such tactics are more typically employed. Police officers are permitted to briefly stop and question a person to dispel the suspicion, and also to frisk the person without a warrant, without violating a person's 4th Amendment rights to be protected from unreasonable search and seizure. (Terry v. Ohio 1968) It is not surprising that the practices have spawned discourse regarding the effect of such aggressive tactics on crime rates, as well as on crime control and crime prevention. Arguably, aggressive policing practices in themselves are deemed justifiable by criminal justice and some political officials to maintain social order and community safety. (Goldstein, 2013, A13) At the same time, however, justification for such practices, based on crime trend outcomes, fosters a growing divide between criminal justice administrators, social science researchers, and the judiciary. (Bratton and Kelling, 2006; Savage and Goode, 2013) In such a context, ideas of crime control and crime prevention are more likely to be discussed as complementary outcomes of each other.

Notwithstanding empirical evidence of declining crime trends both nationally and in local urban locales such as the New York metropolitan area, deeper questions emerge for analytical reflection regarding the nature of police work and future policy initiatives. What really happens when police and citizens meet in suspicion-based encounters? And what is the significance of emotions, such as shame, in such incidents?

While literature in the field more readily addresses to the use of shaming in the formal adjudicatory imposition of punishment to control criminal behavior, the effects of shame on citizens in suspicion-based encounters with police are not typically explored. (see Garvey, 1998, 
745; Massaro, 1991, 1894-1897) At the same time, intended outcomes of shaming in formal arenas of criminal justice are not necessarily predictable. For example, according to Garvey (1998), shaming in the sentencing of offenders does little to address offenders' change of preferences for future behavior $(757,763)$

This paper addresses the nature of suspicion-based encounters between citizens and law enforcement authorities in terms of the implications of shame on all parties, including the community, and is organized as follows: first, a brief discussion of a deeper dimension of crime trend research will suggest the need to address the issue of procedural responses by police from a somewhat different and inter-personal vantage point; second, the significance of shame will be presented as a contributor to perceptions about procedural fairness and justice by stakeholders in police-citizen encounters; third, the pertinence of this development will be discussed in terms of understanding crime control and crime prevention; and, finally, concluding remarks will be presented.

\section{Understanding Crime Trends: Deeper Dimensions}

It is well documented that violent and property crime rates have diminished consistently since 1995 both nationally and in urban locales (Uniform Crime Report, 2010, Tables 1, 1A, 2; Sourcebook, 2010, Table 4.2) Attempts to explain this trend have included the influence of police organizational culture, the politicization of crime data, and police - community relations. (Eterno, 2012; Chayes, 2012; Zhao, Scheider, and Thruman, 2002; National Evaluation, 2000)

Can crime rate trends be meaningfully explained? Zimring (2012) conducted a well-organized data analysis to explain the significant decline in crime rates in New York City amid relatively unchanged social conditions. His research $(2012 ;$ 2007) revealed statistically unremarkable trends in unemployment in New York City during the 1990s, as well as below-national average growth of more crime-prone, younger age groups. At the same time, a declining incarceration rate in the New York metropolitan that remained below the national trend was accompanied by the maintenance of police manpower levels that was greater than those of nine other larger cities in the United States. $(207-209 ; 240)$ What was most apparent, however, was a focus on more aggressive law enforcement tactics in crime-intensive areas. A computerized-data-centered operational program, known as COMPSTAT, relying on "a core set of management principles built around comprehensive crime analysis techniques" and a "culture of accountability" for superiors and line police officers alike, emerged to identify incidence of crime in the New York metropolitan area as well as to evaluate efforts of response by police (Dabney 2010, 29). According to Zimring (2007), this program influ- 
ences the use of aggressive policing tactics at the street level. ${ }^{1}$ (151) Eterno (2012), however, critically views COMPSTAT as placing an "addictive emphasis" on numerical data in police work that has reinforced an institutionalized police "performance culture" in the New York City Police Department and diminished officer discretion in encounters with the public. (A23) At issue then is the prioritization of deterrence measured in terms of crime rate decreases and as an outcome of aggressive police tactics. (see Buntin, 2013)

Zimring's (2007) finding - - that more aggressive policing tactics represent the only real change in criminal justice in New York City and therefore, by process of elimination, most likely explains the decline of crime - - does not address a deeper dimension of police work and its effects on the public. In this regard, while Zimring (2012) concludes, in part, that policing strategies were a determining factor in the statistical decline of crime, he also acknowledges that his methodological approach does not explain the behavior of "human subjects" in such a context. Accordingly, there is a need to address the personal, interactive dimension that underlies behavioral outcomes in police-citizen encounters less addressed by a more exclusive reliance on quantitative crime data analysis.

This paper acknowledges the effect of aggressive policing strategies, at least in part, to explain crime trends but posits that the nature of suspicion-based police encounters with the public, such as in stop and frisk incidents, are social interaction episodes that comprise the presence of shame, a perceived sense of fairness or unfairness, and citizen and police perceptions of self and each other. (Sherman, 1993; Tyler 2000 and 2006; Braithwaite, 2000, 291-292; Dai, 2007; Murphy, 2009B, 173; Gau and Brunson, 2010, 258)

\section{The Presence and Effects of Shame}

Shame is endemic to social control as an outcome of sanctioning experiences and one's involvement in the criminal justice process. (Sherman, 1993; Braithwaite, 2000 and 2006; Gau and Brunson, 2010, 273; Beck, Warner, and Ohmer, 2010, 362) At the very least, while shame is present as an effect of labeling an individual as a suspect or offender, research has been less likely to explore the relation of shame to

1 Zimring (2007) identifies "street intervention practices" as related to the Broken Windows approach introduced by Kelling and Bratton (1988). More specifically, this approach to policing advocates the maintenance of social order by police intervention at relatively benign offense levels in order to prevent escalation to more serious criminality. According to Zimring (2007), the scope of the effect of stop and frisk tactics on crime rates is difficult to evaluate independent of other aggressive policing practices. (155; see also Fagan and Davies, 2000, 497; and, Fagan, Zimring, and Kim, 1998, 1320-1323, in regard to homicide trends in New York City). 
the "subjective world of criminal offenders" in terms of their emotional satisfaction or dissatisfaction with their behavior. (Gray, 2010; Frazier and Meisenhelder, 1985)

The presence of shame in itself does not predict the likelihood of remorse in terms of offenders or suspects. Furthermore, there is no consensus regarding a deterrent effect of being shamed in a sanctioning experience. For example, Braithwaite (2000) maintains that the manner in which shame about criminal behavior is experienced in encounters influences crime rates. (281) He identifies two types of shaming. Integrative shaming by nature is characterized by respectful interaction between authority figure and subject, whereby "the offender is treated as a good person who has done a bad thing." (282) Conversely, shaming can also be "stigmatizing," characterized by disrespect, whereby the offender is treated as a bad person who has done a bad thing. According to Garvey (1998), doubts about the deterrent effect of shame are especially evident when it is stigmatizing: ". . . it may be because the offender is so socially isolated that he already is at risk of engaging in criminal behavior." (752)

Deeper dimensions of the nature of reintegrative shame have broader ramifications. There is consensus among scholars that reintegrative shaming serves to " 'educate' or shape the preferences of individuals who are punished" by " "coupling' . . community disapproval with subsequent gestures of reacceptance and forgiveness." (Note, 2003, 2192) At the same time, however, Braithwaite's ideal construct of community, that provided a social context for reintegrative shaming, is criticized because of the uncertain degree to which persons in fact actually identify with principles of social normative behavior in respective communities. (Massaro, 1991, 1999) Massaro (1991) further argues that the application of effective shaming that is reintegrative is problematic because the culture of modern American urban communities is characterized by an absence or minimization of "high expectations of social responsibility, coupled with close social bonding, . . . and strong family attachment," which are present in cultures that apply effective shaming. (1894; see also Note, 2003, 2194)

Shame, within the context of the relationship between the community and police as agents of social control, has further implications. Kemper (1978) affirms the need for a more comprehensive sociological approach to understand emotions in social situations by a greater focus on "what actually goes on between the actors" in social encounters that represent "relations of power and status." (2, 31, italics added) He further asserts that the use of "excessive power" devalues the status of another, and not only evokes feelings of guilt and shame in the subject but also negates the subject's "claims to ... decency [and] fairness." (68) 
According to Massaro (1991) and consistent with Kemper (1978), shame can diminish the self-image of the shamed person. One might also hypothesize that in racially charged environments, shaming encounters can serve to reaffirm perceived secondary status by minority group members. (see Reisig et et al, 2007) In effect, in subcultural community environments, perceived disrespectful shaming in police practices may convey a certain moral condemnation and is more likely to elicit hostile views toward legal authorities. (Note, 2003, 2191 and 2193) The social cost of such tactics includes the affirmation of a certain perceived sense of alienation by community residents who view themselves as being unequally protected by the law. (Stuntz, 2011, 8)

In their theoretical construct, Scheff and Retzinger (1997) further maintain shame that is disrespectful serves to weaken the offender's social connection or bond to society and may result in a repressive, personal pattern of behavior. In essence, the offender becomes ashamed of being shamed disrespectfully. In this regard, according to Sherman (1993), defiance, based on a perception by the citizen that the authority figure's procedural conduct is unjustified, or illegitimate, and a sense of isolation are more likely outcomes. (also, see Braithwaite, 2000, 291292) And, scholarly discourse further reveals that a sense of fairness or unfairness by citizens in encounters with police officers both in arrest and non-arrest-related incidents influences citizens' long-term compliance with laws. (Murphy, 2009A, 2-3; also, see Tankebe, 2008, and Deutsch, 2006) Deterrence, then, may or may not be an outcome of shaming.

Suspicion-based police-citizen encounters, in which some degree of sanction is possible (e.g., a warning; a summons; a "pat-down"; an arrest), represent experiences that may spawn not only a feeling of shame but also a response to that feeling. (see Tyler 2006) According to Sherman (1993), however, there has been a paucity of research on the effect of shame on citizens who are subject to the authority of police officers in such encounters, and on police officers. For example, in their study regarding police decision-making in non-arrest encounters, Terrill et al (2007) focus on police perception of citizens while excluding citizen perceptions regarding police, which may have an effect on discretion in such incidents. Tankebe (2008) further points out "the failure of the procedural fairness literature" to include potential effects of police officers' "self-conception of their power" to better understand police-citizen encounters. (15)

Finally, the experience of being shamed also has subtle implications regarding one's sense of personal integrity. For example, perceived procedural unfairness in police-citizen encounters based on extra-legal factors such as race have been found to affirm citizens' sense of disrespect 
by police. (Gau and Brunson, 2006; Dai, 2007) In this view, it is the suspect or offender and not the behavior that is labeled as criminal or deviant, and shamed. (Cohen 2001, 212; see also Morrison, 2006, 388) The effects of shaming, then, are influenced by the presence or absence of fairness.

\section{The Matter of Fairness}

In the doing of criminal justice, fairness has varied implications and reveals different underlying mind-sets. For example, Stuntz (2011) accentuates a distinction between the American Bill of Rights and the French Declaration of the Rights of Man and of the Citizen: the former is procedure-centered and emphasizes "being fair" while the latter emphasizes "being just." (74-78) Likewise, according to Whitman (2009), in a broader and cross-cultural perspective, American policies of harsh sanctions to control and prevent crime can be explained by a greater emphasis on fairness as a procedural outcome rather than by a more emphatic focus on respect for the dignity of the individual which is more evident in Europe.

In a similar vein, Michel Foucault, in Discipline and Punish (1977), exploring whether penal reform in more contemporary society is more humane than its brutal past, maintains that the "humanity" ascribed to modern penal systems does not refer to a trait of the offender but rather to a more calculated and proportional sanctioning of offenders. (1977, 92, italics added)

This has implications for suspicion-based encounters between police and citizens wherein emphasis on social control for community safety is directed to the offense or suspected illicit behavior of suspects than the offender or suspect himself. In this regard, Hutson (2013), in an assessment of literature regarding the "psychology of moral consistency," affirms the beneficial effect of focusing on the character of the person for positive reinforcement than the act in negative reinforcement: "Convinced that we're bad, it's hard to go back." (12)

More subtle consequences of justifying the implementation of legal procedures for crime control also are evident. For example, Gopnik (2012), reflects that as systems become procedural and professionalized, the more "insulated" they and all who function or serve within them become from the "real effect ... on real people". (6; also, see Stuntz, 2011, 66-69) Hence, the achievement of fairness by procedural practice may be compromised. (Stuntz,, 2011, 28)

In a comprehensive review of scholarly literature in the field, Tankebe (2009) identifies key characteristic traits that reflect a sense of procedural fairness that extends beyond legal practices. In particular, public perception about the fairness of encounters with police is influ- 
enced by the nature of the communication and citizens' feeling that they are held "in high regard" by authorities. According to Tankebe (2009), the citizen perceives that his or her interaction with police is not aggravated by extra-legal factors. (9) A consequence is a greater likelihood that citizens will view police motives with trust and be able to provide input in police-citizen suspicion-based encounters. (10) Fairness in procedural matters then is informed in part by public perception: "The quality of interpersonal treatment concerns public evaluation that . . . legal authorities treat them with politeness, and dignity and respect their human rights." (10)

Sherman (1993), in his paradigmatic theory of deviance, emphasizes "defiance" as an outcome of the offender's perception of being sanctioned unfairly. This theme also is reflected in policy reports that address "police integrity," typically defined as "the normative inclination among police to resist the temptation to abuse the rights and privileges of their occupation." (U.S. Department of Justice, 2005, 2) In a report of a national conference of police officials, civil rights representatives, and community leaders, the U.S. Department of Justice affirmed the need for law enforcement agents to recognize and respect the value and dignity of every person." (U.S. Department of Justice, 2001, 5) It was emphasized that such a core value, when interwoven within the "culture" of police organizations rather than simply sought as a personal character trait of recruits, can spawn citizens' trust in police that enhances effective crime reduction policies. (3) Additionally, at a national symposium sponsored by the Office of Community Policing Services and the National Institute of Justice, the issue of citizen trust in police was stated poignantly: "Citizens aren't just interested in the results of policing-whether crime rates are down and people are feeling secure. Citizens want to be certain that their police are behaving correctly as well as being effective." (U.S. Department of Justice, 1997, 66)

According to Tyler (2006), sanctioning that is perceived as fair comports with procedural justice, enhances a sense of legitimacy regarding the law and one's personal responsibility to regulate his or her behavior. (313) Tankebe (2009), maintains that "police have an intrinsic nonnegotiable obligation" to treat citizens not only fairly and respectfully but as human beings. (14) Consequently, the interconnectedness of human worth and procedural fairness can influence citizens' evaluative perceptions about encounters with legal authorities.

Furthermore, according to Tyler, legitimacy offsets a sense of social exclusion in citizens that would impede a relationship of honesty and trust with agents of the legal system. In this sense, legitimacy is the equivalent of procedural fairness. (Tankebe, 2009, 12) This in part explains a finding by Tyler (1990), based on empirical data, that legitimacy 
is informed by the "process of fairness" as exercised during interactions than by outcomes. (Tankebe, 2009, 9; also see Bottoms and Tankebe, 2012, 119-121) According to Stuntz (2011), prominent reliance of the contemporary criminal justice system on legal procedures results in a "bureaucratic detachment" between authorities and citizens which may compromise the process that underlies the deeper meaning of procedural fairness. (252)

While police-citizen encounters that are perceived as procedurally fair can spawn a sense of legitimacy in the eyes of the public, perceived unfairness in citizen-police encounters has farther reaching effects. Murphy (2009A), in research that defined procedural justice in terms of fairness, courtesy, and the opportunity to citizens for input in encounters, reveals a significant impact of police practices on citizens: “. . if members of the public perceive police as treating them unfairly, this signifies police do not consider them to be important or valued members of the community." (114, italics added) Reisig et al (2007) accentuate the significance of "social context" factors on police and citizen attitudes and behavior. More specifically, they found that recidivistic behavior by former black male inmates is positively influenced by their return to neighborhood locales characterized by high levels of social inequality, thereby reinforcing a sense of secondary status.

Procedural fairness, both by its presence or absence, and its relationship to shame, has broader implications that are not readily apparent. Shaming can spawn a sense of moral condemnation, and "taken to be representative of a person's entire identity." (Garvey, 1998, 766) Such an outcome is especially likely if the suspect already has developed an "attachment" to criminal subcultural groups in a locale. (749) Hence, unfairness can exacerbate the effects of shame in encounters and, in turn, diminish a sense of legitimacy in regard to the legal system. Kemper (1978) further maintains that power and status inform all social relationships. In this regard, verbal abusive remarks by authority figures can serve to reduce claims of "status" by citizens as "dismissible." (31) In such incidents, citizen compliance is likely to be made only "to avoid even further debasement." (30)

The significance of the effect of the process underlying perceived procedural unfairness, as well as its effect on community attitudes is illustrated by a recent class action suit brought by African-American and Latino plaintiffs who are residents of the Bronx, New York, against the City of New York and the New York City Police Department, contesting the department's stop and frisk policy. (Jaenean Ligon v. City of New York, 2013) The presiding Federal judge found in part that police stop and frisk encounters with citizen-residents were unconstitutional based on the nature of the encounters. While the case is contested on constitu- 
tional grounds, the nature of the case facts and judicial reflections on record are especially noteworthy. In particular, the case record reveals that when residents were stopped and questioned by police about their presence and purpose for being in the area, "attempted explanations were met with hostility; especially if the person is a young black man, he is frisked, which often involves an invasive search of his pockets; in some cases, the officers detain the person in a police van." (32-33, italics added) The judge commented reflectively on an earlier era of policing wherein "a local officer might have politely posed these questions to a stranger ... and the stranger might have gladly consented to answer the questions . . . out of politeness or a sense of civic duty." (98-99, italics added) Similarly, Gau and Brunson (2010), in their study of "order maintenance" policing strategies that include stop and frisk practices, found that while young urban males in "disadvantaged neighborhoods" understood that "suspicion-based stops" by police were conducted to insure community safety, the frequency and nature of such encounters served to diminish the legitimacy of such practices in the eyes of individuals and the community. (264)

Tyler and Wakslak (2004), in four research studies, further explored the effect of citizens' feeling profiled in comparison to being profiled based on their perceptions of police acting (or failing to act) with procedural fairness. (254-255) Notably, they found that citizen and community support for police, and the acknowledgement of legitimacy of police actions in encounters, were less likely affected by trust in the motives of police as authority figures and more likely influenced by the actions of police who were perceived as "neutral" and respectful. (257) Hence, the psychology of police encounters with the public provides a context in which to further understand the effect of perceived on citizen, officer, and community attitudes and behavior in such incidents. (see Bottoms and Tankebe, 2012, 160; Bayley, 2002)

The use of aggressive police tactics in suspicion-based incidents, then, must be evaluated by the manner in which they are exercised and experienced by the stakeholders in such encounters. Research has identified police organizational culture as an aggravating factor in this regard. For example, Gau and Brunson (2010) found that order maintenance practices that accompany "quality of life" stops and arrests for lowerlevel offenses are not as defined as are higher-level offense procedures. ${ }^{2}$ As a result, police may be more likely to rely on "extra-legal" factors such as race and neighborhood in initiating encounters with citizens. (258) Furthermore, in an ethnographic study, Dabney (2010) found that

2 "Quality of life" stops and arrests are made to promote and maintain a more secure neighborhood environment based on the premise that even low level suspicious behavior will not be tolerated in the community. (see Kelling and Bratton, 2003) 
officers tend to consider the organizational focus on statistical data as a "numbers game" to reflect the effectiveness of precinct operations that is measured by arrests for felony and misdemeanor offenses without distinction. (39-40) In essence, police discretion becomes compromised and line officers feel pressured to make a greater number of arrests, even amid a statistical decline in area crime in order to satisfy superiors. While the pertinence of police organizational culture is not misplaced, it obscures a deeper concern regarding police officers' sense of themselves in terms the power they possess, the sense of the "moral rightness of their powers," and officers' relationship to the community. (Tankebe, 2009, 15)

\section{IMPLICATIONS REGARDING THE EXPERIENCE OF JUSTICE}

The relationship of shame, a sense of fairness, and legitimacy that characterize the nature of encounters between police and citizens, informs the experience of justice. (Braithwaite, 2000, Tyler, 2006, and Sherman, 1993) Discussions of justice in criminal matters, however, tend to focus more on its implementation than the meaning of justice. Von Hirsch (2007), however, critically reflects that retribution in criminal matters conveys a certain moral dichotomy of good versus evil. This can lead to a "dualistic fallacy" of thinking that simply distinguishes the criminal from the non-criminal person as distinct entities. (see Hagan, 2008, 16, 66, 174-175)

Braithwaite (2006) constructs a broader landscape of meaning regarding justice. He proposes an integrative idea of justice that encompasses "legal justice," identified with the criminal justice system, and "social justice" identified with systems of social welfare. (398) He asserts, however, that attempting to achieve such dual-dimensional justice is not possible within a more exclusively retributive systemic framework that seeks to "deliver equal punishment for equal wrongs." $(398,399)$ In essence, within a more retributive context that aims to make sanctions proportionate to categories of similar offenses, a more individualized approach to justice is compromised. This, in turn, may diminish the public's belief in the "legitimacy of legal authorities" and that justice has been done. (Tankebe, 2009, 9)

Tyler (2006) further points out that the perception of procedural justice as fairly exercised contributes to citizens' compliance with the law and can be a basis for an effective system of formal legal control: "people accept as their own feelings of responsibility and obligation for their actions in society." (313; also see 320-321) And Braithwaite (2006) asserts that in such instances, a person is less likely to perceive that respect for his/her rights has been violated by discrimination. (398) 
It is clear, therefore, that the meaning and effect of police-citizen encounters are defined by more than the exercise of procedural tactics. Rather, the manner in which decisions are made and carried out in encounters influence citizens' sense of justice and as well as their behavior. Such a view, however, necessitates acknowledgement of the limits of a more exclusively retribution-centered idea of justice. The punitive, retribution-oriented ideology that has governed the American approach to justice in criminal matters since the 1970s has resulted in a more "negative relationship between the police, courts, and residents of American communities."'(Tyler, 2006, 308) And, Nagin (1998) concludes that legal authorities may tolerate negative consequences as necessary crime control practices to maintain social order.

An alternative approach to justice, founded philosophically on respect for the dignity of persons, is restorative in nature and consistent with Braithwaite's idea of reintegrative shaming. The idea of restorative justice has historical roots but has developed since the 1970s, and is operative in more than three-hundred jurisdictions throughout the United States. (Van Wormer, 2001, 33) According to Bazemore (2007), in this context, crime or illicit behavior not only is a violation of law but harms victims, communities, and offenders alike. Furthermore, each of the three "stakeholders" of crime incidents - - victims, the community, and the offenders - - assumes a responsibility in support of one another to effect reparation and influence future behavior. (Clear and Dammer, 2003, 328) Citizens, then, become each other's keeper! In such an environment, premised on a belief in the dignity of the human person, the sense of justice "does not center on shame" but rather "focuses on obligation and responsibility." (Tyler, 2006, 320)

The meaning of restorative justice in criminal and sanctioning matters, therefore, necessarily includes a communitarian dimension which, according to Tyler and Wakslak (2004), is more likely to enhance police management of encounters by their treatment of those whom they serve. (276) This in turn represents a vital element of the efficacy of the community policing model in its deeper dimensions. In particular, in establishing a partnership with the community, police are challenged to make distinction between "social control" and "coercive control" and socialize residents to identify and report ominous situations and persons to police. (see Beck, Warner, and Olmer, 2010). But it also makes demands on police to become more deeply identified with neighborhoods in a community-centered and respected guardian role. Such an understanding of guardianship typically would be less likely in locales where residents have low levels of trust in police. (e.g., see Gau and Brunson 2010) The implementation of police tactics, such as stop and frisk, when undertaken in a community to which police are identified culturally and profession- 
ally, requires the police to be more than providers of professional enforcement services to a community, or as Dai (2007) concluded, police and citizens become "co-producers of public safety." (123, italics added; see also Davis, 2012)

\section{Implications for CRime Control ANd CRIME Prevention Strategies}

Crime control and crime prevention as co-dependent outcomes of aggressive policing practices such as stop and frisk must be assessed within the context of the nature of police-citizen encounters. Based on the foregoing development, order maintenance is not measured simply by crime rates but is influenced by public perception of procedural fairness and legitimacy of police practices which informs citizens' sense of procedural justice and their behavior.

Wilson and Kelling (1982) initially proposed the Broken Windows policing strategy which provided a theoretical context for aggressive police tactics, such a stop and frisk. They utilize an analogy to "broken windows" to describe the effect of neighborhood disorder on crime and community safety. Conversely, social order contributes to a sense of safety in the community by enhancing residents' shared identity and investment in the neighborhood. $(29,36)$

In such an environment, police serve a means to "elevate . . the level of public order" by an enforcement presence in the community. Police are more proactive and intervene in more benign patterns of disorderly behavior (e.g., drinking in public, prostitution, vandalism, defacing property) in order to prevent more serious criminal acts and greater community fear. (34): This approach envisions a community that more cohesively engaged in maintaining social order, than relying on "law enforcement per se." (36)

Wilson and Kelling (1982), however, provide a less defined account of the ramifications of the nature of police interaction with the public in those community environments. For example, they acknowledge that the effect of broken windows on "fair treatment" of residents is problematic, since broken windows tactics are likely conducted in neighborhoods in which all or most residents are racial minority members. (36; also, see DeStefano 2014) This concern, however, is not discussed more specifically except to infer that a resolution would involve the need for police officers, through training and supervision, to develop "a clear sense of the outer limits of their discretionary authority." (35) As a result, while Broken Windows conveys a certain centeredness on police not only as enforcement agents for regulation of behavior but as facilitators of order in the community, it less clearly identifies deeper implications of the 
nature of interaction between police and the public in locales deemed to be disordered, on community safety.

The Broken Windows policing strategy has spawned scholarly discourse regarding its theoretical premise and applied outcomes. For example, Harcourt (1998), in his research regarding the relation of social disorder and crime in New York City, found a causal link between ordermaintenance and the effects of aggressive policing. He argues, however, that aggressive policing tactics are legitimized as regulatory efforts and not necessarily in terms of any deterrent effect: "[stop and frisk tactics to improve "quality of life" in communities] have little to do with fixing broken windows and much more to do with arresting window breakers or persons who look like they might break windows, or who are strangers, outsiders, or disorderly." (28)

In 2006, Bratton and Kelling, in an apologetic response to their critics, posited that neighborhood disorder creates citizens' fear of crime which diminishes social controls and creates an environment where crime can more readily exist. (78) They further argued that the "real world" demands that focus be prominently placed on procedural enforcement than on fixing broken windows environments.

Crime control and crime prevention, as complementary outcomes, however, encompass more than procedural control strategies. The perception of the community about the experience underlying these practices is most pertinent to social control outcomes. (Massaro, 1991, 1898) This is empirically supported in a recent study by Fratello, Rengifo, and Trone (2013) who surveyed about 500 people, 18 to 25, and also interviewed a smaller sample of 13- to 21-year-olds" in five high crime communities in the New York metropolitan area where residents were more likely to be stopped and questioned by police. Their research addressed the effect of such encounters on citizens and found that of those surveyed, $88 \%$ do not believe residents in their neighborhood trust police, only $24 \%$ would report a person whom they knew committed a crime, $40 \%$ would report a crime that they witnessed, and $41 \%$ would report a crime that victimized them. (17) This study also found that those surveyed maintained a strong racial-ethnic identity, as well as a sense of self-confidence and self-reliance (19), in spite of the overwhelming negative perceptions of police practices in their neighborhood life experiences. Weitzer (2000), in ethnographic research that compared a black lower-class neighborhood to respective white and black middle-class neighborhoods, further found that the social class structure of black neighborhoods may, at least in part, influence the attitudes of residents 
toward police. ${ }^{3}$ Bayley (2002) emphasizes that residents' perceived sense of alienation by police discourages residents' cooperation with police and aggravates neighborhood hostility toward the system of law and its agents. In effect, then, both control and prevention of crime as complementary outcomes of aggressive police tactics are compromised. Attempting to address the matter of community safety without deeper acknowledgement of the effects of police-citizen suspicion-based encounters, then, is at best problematic.

As developed in this paper, control-based policing tactics for crime deterrence that generate public perception of procedural unfairness not only result in adverse reactions by the targeted communities and their residents, but also fosters a sense of social exclusion and broader skepticism regarding equity in the system of law. While deterrence-centered policing practices can contribute to crime control, at least based on reported diminishing crime trends, the realization of crime prevention goals require the implementation of procedures in a manner that will affect future behavioral decisions by citizens. Therefore, prevention of crime, which encompasses both the exercise and social perception of legal procedural implementation, cannot more simply be viewed as a contemporaneous outcome of crime control practices.

\section{CONCLUSIONS}

While crime rate data have served as a primary unit for analysis to evaluate community safety, their ramifications for crime control and prevention have not been more aggressively addressed. This paper, by a critical assessment of criminal justice and social scientific literature, has argued that suspicion-based encounters between police and citizens are characterized by the experience of shame that is inter-related with a perceived sense of fairness and justice whose effects extend to citizens, police officers and communities as stakeholders. As a result, traditional understanding and ramifications of crime control and crime prevention, as antecedents for community safety, must be revisited.

The nature of social interactive experiences in suspicious encounters between police and the public elicits citizens' perceptions regarding fairness or unfairness, and, based on findings of theoretical, analytic and empirical studies, affect both residents and their neighborhood communities. (Sherman, 1993; Braithwaite, 2000; Tyler and Wakslak, 2004; Tyler, 2006; Tankebe, 20008; Gau and Brunson, 2010) As a result, stop and frisk as an aggressive police tactic reveals deeper dimensions of meaning in regard to crime control and prevention. Fratello, Rengifo, and

3 Data compiled in research by Fratello, Rengifro, and Trace (2013) strongly imply that negative community perceptions regarding implementation of police stop and frisk tactics may also breed stronger racial group solidarity. 
Trone (2013), in their study of the effects of stop and frisk on the public, identified an effect among racial/ethnic minority groups targeted for more aggressive policing tactics: "younger members of these racial and ethnic groups have such low opinions of police that they are unlikely even to report a violent crime against themselves. (21) Furthermore, data reveal that while the young residents of high-crime communities surveyed for this study reported high-levels of distrust of police officers, they also expressed a certain optimism founded on a strong racial identity and a feeling of trust by their friends. (20) What might comprise this "optimistic" self-view that seemingly coexists with young people's skepticism about the legitimacy of the system of law and its agents? ${ }^{4}$ Would police-citizen encounters in suspicion-based incidents founded on a respect that Braithwaite (2000) describes in regard to reintegrative shaming serve to facilitate a sense of self-confidence among citizens that is informed by perceived legitimacy of law and its agents? In this regard, there is a need to more deeply understand the effect on police officers' self-perception of the manner in which they carry out procedures in terms of their own sense of legitimacy as authority figures in encounters. (see Bottoms and Tankebe, 2012)

The social community context in which police and citizens encounter each other influences the manner in which police practices are experienced - - not only by citizens but by law enforcement officers themselves. According to Weitzer (2000), the social class structure of neighborhoods inform citizen perceptions of police and is predictive of policing strategies which are more likely to be proactive than reactive in poorer neighborhoods. (143) Accordingly, there is a need to understand "neighborhood-specific relations" between police and residents by a neighborhood contextual research approach. (152). Kemper (1978) affirms that even one-time meetings spawn perceptions in both stakeholders whether residents were previously known to police or not known. Consequently, in view of the influence of the social environment on citizen perceptions and attitudes, as well as on those of law enforcement officers, there is a need to develop and include programs of cultural awareness that combine service and learning, in police training curricula. In this regard, Bayley (2002) proposes that police are more likely persuaded by "evidence-based" training that maintaining a human rights sensitivity in implementing legal procedures facilitates the control and prevention of crime. (135) The learning objectives of such training

4 This finding by Fratello, Rengio, and Trone (2012) is consistent with the results of social psychological research by Asencio (2013) that affirms principles of identity theory; namely, that appraisals by members of one's social networks of trusted others serve to support one's self-image than appraisals by criminal justice agents. 
should extend to experiential awareness of the process underlying different citizen outlooks and response in these encounters.

The goals of crime control and crime prevention, when politicized, tend to be presented as contemporaneous effects of aggressive policing tactics. However, the nature of police-citizen encounters emphasizes the need for criminal justice policy initiatives to address control and prevention of crime as outcomes of a longer-term and more complex process correlated not simply to procedural tactics but to the social context in which they are implemented. The result may be a new path to deterrence based on a deeper understanding of the nature of police encounters with the public and their effects on shaping the attitudes, behavior, and sense of justice among citizens, the community, and law enforcement agents alike.

\section{REFERENCES}

Asencio, Emily. (2013). Self-esteem, reflected appraisals, and self-views: Examining criminal and worker identities. Social Psychology Quarterly 76(4), 291-313.

Bayley, David. (2002). Law enforcement and the rule of law: Is there a tradeoff. Commentary 2 (1), 133-154.

Bazemore, G. (2007). The expansion of punishment and the restriction of justice: Loss of limits in the implementation of retributive policy. Social Research, 74 (2), 651-662.

Beck, Elizabeth, Warner, Barbara D., and Ohmer, Mary L. (2010). Linking informal social control and restorative justice: Moving disorganization theory beyond community policing. Contemporary Justice Review 13 (4), 355-369.

Bottoms, Anthony and Tankebe, Justice (2012). Beyond procedural justice: A dialogic approach to legitimacy in criminal justice. The Journal of Criminal Law and Criminology 102 (1), 119-170.

Braithwaite, John. (2000). Shame and criminal justice. Canadian Journal of Criminology 42 (3), 281-298.

(2002). Setting standards for restorative justice. British Journal of Criminology 42, 563-577.

Buntin, John. (2013, July 14). What does it take to stop crips and bloods from killing each other? The New York Times, pp. 38-55.

Bratton, William J. and Kelling, George. (2006). There are cracks in broken windows. National Review (On-line). Available: http://old.na tionalreview.com/comment/bratton_kellking200602281015.asp

Buntin, John (2013, July 14). Peace in gangland. New York Times Magazine, 36-39, 44, 54-55. 
Chayes, Matthew. (2012, August 2). False stats at two precincts. Newsday, p. A 2.

Clear, T. and Dammer, H. (2003). The offender and the community 2nd $E d$. Belmont, CA: Wadsworth.

Cohen, Ronald L. (2001). Provocations of restorative j ustice. Social Justice Research 14 (2), 209-232.

Dabney, Dean. (2010). Observations regarding key operational reality in a Compstat model of policing. Justice Quarterly 27 (1), 28-51.

Dai, Mengyan. (2007). Procedural justice during police-citizen encounters. Unpublished Doctoral Dissertation. University of Cincinnati.

Davis, Michael A. Community building as crime control. American policing in 2022: Essays in the future of a profession. Eds. Debra Cohen McCullough and Deborah L. Spence. 2012. Washington, DC: U.S. Department of Justice, 29-32.

DeSterfano, Anthony (2014, August 5). Crime analyst stands by 'windows' tactic. Newsday, p. A 28. (2013, January 9). NYPD loses ruling. Newsday, p. A5

Deutsch, Morton. (2006). A framework for thinking about oppression and its change. Social Justice Research 19 (1), 7-41.

Doolin, K. (2007). But what does it mean: Seeking definitional clarity in restorative justice. Journal of Criminal Law, 71 (5), 427-440.

Dorne, C.K. (2008). Restorative justice in the United States. Upper Saddle River, NJ: Prentice-Hall.

Eterno, John.A. (2012, June 18). Policing by numbers. The New York Times, p. A 23.

Fagan, Jeffrey and Davies, Garth. (2000). Street stops and broken windows: Terry, race, and disorder in New York City. Fordham Urban Law Journal 28 (2), 455 - 504.

Fagan, Jeffrey, Zimring, Franklin, and Kim, June. 1998, Declining homicide in New York City: A tale of two trends. Journal of Criminal Law and Criminology 88 (4), 1277-1323.

Foucault, Michel. (1977). Discipline and Punish. London: Allan Lane.

Fratello, Jennifer, Rengifo, Andres F., and Trone, Jennifer. (2013). Coming of age with stop and frisk: Experiences, self-perceptions, and public safety implications. New York: Vera Institute of Justice.

Frazier, Charles.E. and Meisenhelder, Thomas. (1985). Exploratory notes on criminality and emotional ambivalence. Qualitative Sociology 8 (3), 266-284. 
Garvey, Stephen P. (1998). Can shaming punishments educate? Cornell Law Faculty Publications Paper 277, 733-794.

Gau, Jacinta.M. and Brunson, Rod K. (2010). Procedural and order maintenance policing: A study of inner-city young men's perceptions of police legitimacy. Justice Quarterly 27 (2), 255-279.

Gopnik, Adam. (2012, January 30). The caging of America. The New Yorker, 3-13.

Gray, Rebecca. (2010). Shame, labeling and stigma: Challenges to counseling in alcohol and other drug settings. Contemporary Drug Problems 37, 685-703.

Hagan, Frank. 2008. Introduction to Criminology-6th Ed. Thousand Oaks, CA: Sage.

Harcourt, Bernard J. (1998). Reflecting on the subject: A critique of the social influence conception of deterrence, broken windows theory, and order-maintenance policing New York style. Michigan Law Review 97 (2), 291-388.

Hutson, Matthew (2013, August 18). Good deeds gone bad." The New York Times, p. 12.

Jaenean Ligon v. City of New York, 12 CV 2274 (S.D.N.Y. 2013)

Kelling, George L. and Bratton, William J. (2003). Declining crime rates: Insiders' view of the New York City story. In Controversies in Criminal Justice. (ed.) Schoot H. Decker, Leanne F. Alarid, and Charles M. Katz. Los Angeles, CA: Roxbury Publishing.

Kemper, Theodore D. (1978). A Social Interactional Theory of Emotions. New York: John Wiley and Sons.

Massaro, Toni. (1991). Shame, culture, and American criminal law. Michigan Law Review 89, 1-59.

Morrison, Brenda. (2006). School bullying and restorative justice: Toward a theoretical understanding of the role of respect, pride, and shame. Journal of Social Issues 62 (2), 371-392.

Murphy, K. (2009A). Procedural justice and affect intensity: Understanding reactions to Regulatory authorities. Social Justice Review 22, 130 .

(2009B). Public satisfaction with police: The importance of procedural justice and police performance in police-citizen encounters. The Australian and New Zealand Journal of Criminology 42 (2), 159-178. 
Nagin, D.S. (1998). Criminal deterrence research at the onset of the twenty-first century. In M. Tonry (ed.), Crime and justice, 23, 1-42. Chicago: University of Chicago Press.

National Evaluation of the COPS Program. 2000. National Institute of Justice. Washington, DC.

Note: Shame, stigma, and crime. (2003). Evaluating the efficacy of shaming sanctions in criminal law. Harvard Law Review 116 (7), 2186-2208.

Papachristos, Andrew W., Meares, Tracey L., and Fagan, Jeffrey. (2012). Why do criminals obey the law: The influence of legitimacy and social networks on active gun offenders. The Journal of Criminal Law and Criminology 102 (2), 397-442.

Riesig, Michael.D., Bales, William D., Hay, Carter, and Wang, Xia (2007). The effect of racial inequality on black male recidivism. Justice Quarterly 24 (3), 408-434.

Savage, Charlie and Goode, Erica (2013, August 13). Judge rejects New York's stop-and-frisk policy. The New York Times. p. A1, A16.

Sherman, Lawrence (1993). Defiance, deterrence, and irrelevance: At theory of criminal sanction. Journal of Research in Crime and Delinquency 30 (4), 445-473.

Scheff, Thomas. and Retzinger, Suzanne. (1997). Shame, anger, and the social bond: A theory of Available: http.www.TASA.org/library/ pdfs/TAASAL library/49.pdf

Sourcebook of Criminal Justice Statistics. (2010). Department of Justice, Bureau of Justice Statistics. Washington, DC. Available: http:// www.albany.edu/sourcebook/pdf/t422010.pdf.

Stuntz, William. J. (2011). The collapse of American criminal justice. Cambridge, MA: Harvard University Press.

Tankebe, Justice. (2008). Policing, procedural fairness and public behavior: A review and critique. International Journal of Police Science and Management 11 (1), 8-19.

Terrill, William and Paoline, Eugene A. (2007). Non-arrest decisionmaking in police-citizen encounters. Police Quarterly 10 (3), 308331.

Terry v. Ohio, 392, U.S. 1 (1968)

Tyler, Tom. (2006). Restorative justice and procedural justice: Dealing with law-breaking. Journal of Social Issues 62 (2), 307-326. 
Tyler, Tom. R. and Wakslak, Cheryl .J. (2004). Profiling and police legitimacy: Procedural justice, attributions of motive, and acceptance of police authority. Criminology 42 (2), 253-281.

Uniform Crime Report. (2010). Federal Bureau of Investigation, Department of Justice, Washington, DC. Available: http://www.fbi.gov/ about-us/cjis/ucr/crime-in-the-u.s/2010/crime-in-the-u.s.-2010/index-page

U.S. Department of Justice (1997). Police integrity: Public service with honor. National Institute of Justice, Washington, DC.

U.S. Department of Justice. (2001). Principles for promoting police integrity: Examples of promising police practices and policies. Office of Justice Programs, Washington, DC.

U.S. Department of Justice (2005). Enhancing police integrity. Office of Justice Programs, Washington, DC.

Von Hirsch, Andrew. (2007). The "desert" model for sentencing: Its influences. Social Research 74 (2), 413-434.

Van Wormer, K. (2001, November). Restoring justice. USA Today, 3234.

Weitzer, Ronald. (2000). Racialized policing: Residents' perceptions in three neighborhoods. Law and Society Review 34 (1), 129-155.

Whitman, James. (2007). What happened to Tocqueville's America? Social Research 74 (2), 251-268.

Wilson, James Q. and Kelling, George L.(1982, March 1). The police and neighborhood safety: Broken windows. The Atlantic Monthly, 29-38.

Zhao, Jihong, Scheider, Matthew, and Thruman, Quint. Funding community policing to reduce crime: have COPS grants made a difference? Criminology and Public Policy 2 (1), 7-32.

Zimring, Franklin. (2007). The Great American Crime Decline. New York, NY: Oxford University Press.

(2012). The City That Became Safe. New York, NY: Oxford University Press. 